\title{
Modeling the interaction between environment and the economy considering the impact on ecosystem
}

\author{
Viktor Koval ${ }^{1, *}$, Inesa Mikhno $^{2}$, Olena Trokhymets $^{3}$, Liliya Kustrich $^{4}$, and Nataliia Vdovenko ${ }^{5}$ \\ ${ }^{1}$ Odessa Institute of Trade and Economics of Kyiv National University of Trade and Economics, Odessa, Ukraine \\ ${ }^{2}$ European University, Kyiv, Ukraine \\ ${ }^{3}$ Classic Private University, Zaporizhzhia, Ukraine \\ ${ }^{4}$ Uman National University of Horticulture, Uman, Ukraine \\ ${ }^{5}$ National University of Life and Environmental Sciences of Ukraine, Kyiv, Ukraine
}

\begin{abstract}
The problem of anthropogenic impact is becoming more acute every year. The basis of entrepreneurship is to maximize profits and increase profitability ratios. However, when calculating economic indicators, changes in the natural potential and the impact of any activity on the environment are not analyzed. In developed countries, more and more emphasis is focused on socially and environmentally conscious entrepreneurship, however, business is still predominant in the world, where the result of activity is an increase in financial resources due to environmental degradation. At the same time, there is an improvement in the situation with financing environmental protection activity. An increase of the population's consciousness is of a point-like nature, while the ecosystem continues to degrade. It is proved that the negative externalities that were described in the model by Pigou, Leontyev-Ford and others must be taken into account. The necessity of taking waste minimization and negative impact on the environment as a target function is justified. It is proposed to solve this problem systematically and to take into account the effect of the accumulation of negative implications of the impact on the ecosystem.
\end{abstract}

\section{Introduction}

The contemporary state of economic development is characterized by significant human interaction with the environment and a permanent change in the economic and ecological systems. Rapid dynamics and an increase in the links between influence factors become the reason for the emergence of new tools for managing and monitoring systems and is the driving force behind the implementation of new technologies and research methods. The economic condition of the state is described by macro indicators, which are expressed mostly in monetary value, while the environmental component and environmental impact are not taken into account in the calculation.

Population growth is one of the factors contributing to the emergence of many types of environmental stress. The role of the growing population is particularly evident in the fact that it is a major factor determining the need for increased food production. And with the expansion of production and the emergence of new goods, the number of gradually accumulating residues is increasing significantly. Most of all this problem is faced by developing countries that have not yet fully complied with environmental legislation, slow investment in the environmental sector and the introduction of the latest environmental technologies.

After the industrial landscape became a major economic and cultural presence in large cities, creating urban deserts and conversion of industrial into other functions necessary to take care of the natural component in order to be competitive at the European and global levels. Currently, the environment represents the ensemble of natural and artificial elements in which life evolves or the sum of the factors external to the human body such as: the atmosphere, the light, as well as all the other beings [1].

There is a link between the quality of life, living standards and the anthropogenic impact on the social and natural environment [2], because industrial facilities are extremely unequally distributed in the region. Industrial facilities are concentrated in cities and large settlements and provide a significant negative impact not only on the environment, but also create an uncomfortable living environment for the population. Regions of technogenic contamination with an extremely tense ecological situation are reinforced by a non-natural landscape. Currently, industrial facilities that have stopped their production activities are not enough investigated, but continue to provide a strong anthropogenic impact on the environment, since the disposal of industrial waste creates a tense ecological

* Corresponding author: victor-koval@ukr.net

( $)$ The Authors, published by EDP Sciences. This is an open access article distributed under the terms of the Creative Commons Attribution License 4.0 
situation and poses a threat to the natural environment and population [3].

Many methods of investigation have been created to study the influence of man on the ecosystem, using the radiointerferometry technology of navigation satellite signals, it is possible to study ionospheric disturbances that move and are caused by large urban agglomeration [4].

An integrated assessment of the level of resistance of natural complexes to anthropogenic impact by detecting landscape factors of geosystems makes it possible to determine landscapes with different levels of stability potential (from relatively stable to weakly stable).

This requires various approaches in the development of environmental management structures, which the state should provide [5].

However, the modern ecology of the mining and processing industries is more economically oriented and it comes down to minimizing expenses and penalties for environmental damage. Mining enterprises are a source of anthropogenic cadmium entering the hydrosphere and soil. Cadmium can accumulate in plants and living beings, and then spread through food chains and adversely affect human health [6].

The ecosystem is exposed to constant negative impact also due to an increase in the amount of garbage as a result of human activity. The macroeconomic instability in Ukraine makes the garbage processing industry unattractive for investments, but with the help of tax incentives and taking into account the current level of salary in comparison with European countries, the situation can be improved [7].

Today, a model of a "circular economy" has been created, which offers to consider the impact of human activities on the environment, but this concept has been fully implemented in any country [8].

An ecosystem which is characterized by optimized consumption of energy and materials, minimal garbage generation and contamination and the use of any residues produced as raw material is considered to be highly effective. A key constituent of the interaction of environmental and economic components is to increase the efficiency of resource usage with the help of circulating materials and to minimize negative impacts, including from the accumulation of garbage from any activity.

\section{Materials and methods}

The garbage problem accompanies Ukraine throughout all the years of existence, however, the problem arose much earlier in the years of the planned economy and independent Ukraine, as a result, there were many both household and harmful industrial wastes. Alongside with the growth of the economy, population and consumption sphere, there is a rapid increase as volumes as types of waste, primarily industrial, household, and more recently, in particular, waste electrical and electronic equipment, batteries, used tires, vehicles, etc. However, I consider that Ukraine received from the planned economy a significant amount of waste that had been accumulated on its territory for many years due to an ineffective economic policy and thanks to the unresolved issue of waste management to independence. The main prerequisites for the development of the waste management industry are shown in Fig. 1.

As fig. 1 shows all the prerequisites for the development of the recycling process are significant, socially and environmentally-economically justified. The diagram does not present one more powerful socio-economic factor - the desire of the population to use an environmentally safe external environment, and hence, according to the Hicks theorem, bear the expenses of improving the environment [10]. In the last few years, the population or enterprises have been paying money to restore the environment, which has become another impetus to the development of waste disposal. The accumulated funds can be spent on the development of this industry and the introduction of new technologies. In developed countries, in general, these payments are larger, a better waste audit system, which contributes to the creation of more environmentally friendly production, the introduction of recycling, while undeveloped countries and developing countries have a lower environmental tax burden and are not able to develop independently the recycling sector without attracting investors. This is reflected in disposal methods, where recycling predominates in developed countries, while dumping of wastes is more preferable in less developed countries [11].

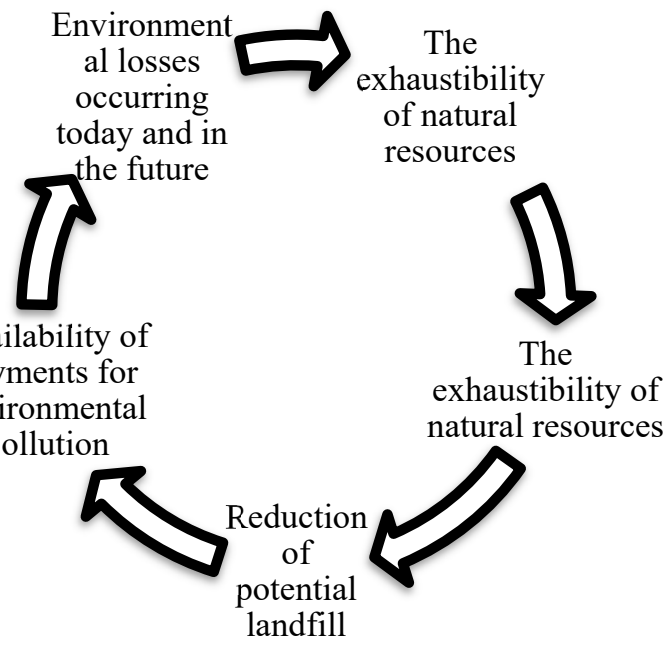

Fig. 1. Prerequisites for Waste Disposal [9]

The composition of household waste differs in different countries and regions, and that's why the methods of disposal through the specifics of the region, legislative support for the use of sorting and recycling differ. Only a small part of garbage is recycled in Ukraine (Fig. 2), and this leads to the constant accumulation of garbage and environmental contamination. 
As it is seen on fig. 2 the amount of household waste is growing alongside with a growth in living standards of population. In the days of political and economic crisis caused by the 2014 revolution, which caused inflation and a decrease in demand for products, there is a slight reduction of the rate of accumulation of waste (by 3,753 thousand tons), while with the stabilization of the economy, the quantity began to grow again to almost 12 million tons in year. The most influence of the economic crisis was experienced by waste management, which fell from 9,4 to 3,8 thousand tons. That's why scientists can conclude that the percentage of disposed waste depends on the economic condition of the country and is directly proportional to its gross domestic product.

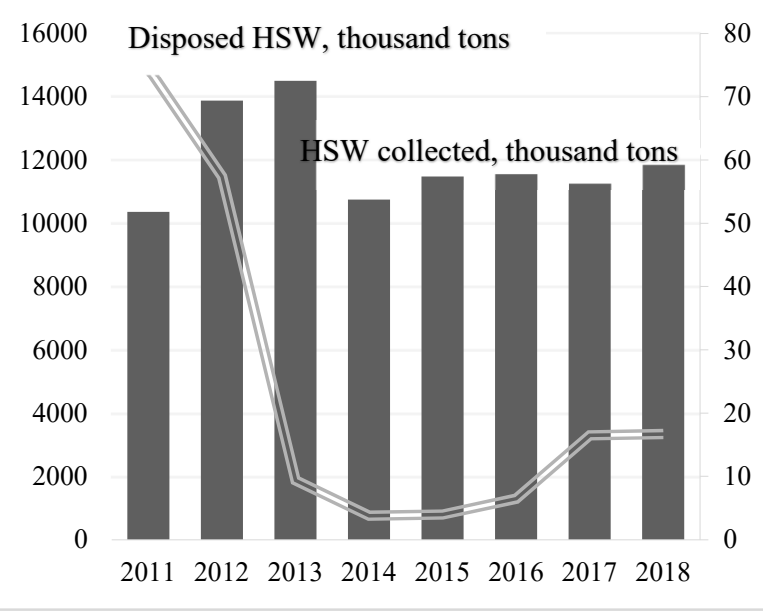

Fig. 2. The Management of Household Waste on the Time Interval in Ukraine [12]

V. D. Parondzhanov concluded that at the first stage of its existence, the GNP indicator adequately reflected the volume of goods and services produced and therefore could indeed serve as an indicator of wealth. But over time, the situation has changed. The rapid growth of population, even faster rise in consumption, depletion of natural resources, increasing the burden on the environment caused the emergence of new and unexpected problems. There was a need to spend significant funds on so-called corrective measures aimed at combating resource depletion, environmental pollution, various disasters, losses, and addressing acute social problems [13].

As a result, the planetary scale has changed in the bowels of the economy, which, however, has gone unnoticed by most economists, let alone the Heads of State and Government. The crux of the change is that a fundamentally new type of expense has emerged and has grown, called "corrective action expense."

\section{Results}

Analysis of the current environmental monitoring system in Ukraine shows that it has not yet become an important tool for effective environmental quality management, timely warning of the harmful effects of pollutants on the air, water, soil, health and well-being of the population, as well as public awareness. on the state and trends of environmental change.

The current state monitoring system only partially provides accurate and reliable quantitative information on the current levels of harmful or potentially harmful substances in the environment. The main purpose of the current monitoring system is not to minimize management measures to protect, preserve and restore the quality of the environment.

In O. Korzhevskaya's work, a modification of the Leontief-Ford dynamic model was proposed, which, in addition to the main indicators, takes into account the release of pollutants during the main and ancillary production, the cost of maintenance of emissions under the Kyoto Protocol, and pollution arising from consumption of products. This technique is one of the foundations of production in our opinion and takes into account the production waste and the impact on the environment [14].

The concept of "Zero waste" [15] should become the basis for the development of society where the profit would be calculated in all branches taking into account the expenses aimed on returning the external environment to its original state.

The target function of the green model is as follows:

$$
\begin{gathered}
F_{1}(x)=\sum_{i=1}^{n} x_{i} \rightarrow \max \\
F_{2}(y)=\sum_{i=1}^{m} y_{i} \rightarrow \min
\end{gathered}
$$

where $x_{i}$ - is the amount of profit on the sale of goods, and $y_{i}-$ the sum of negative externalities, which must be reduced to zero to neutralize business activity. That is maximize the product in $n$ sectors and minimize waste coming into being in the production process.

Pigou's theory of public welfare is the basis for a rational environmental management approach. According to this theory, environmental pollution is regarded as externalities. The essence of this term is that the market mechanism does not transform the external costs borne by society from pollution into internal costs of production, which is not reflected in the prices of products of polluting enterprises.

Externalities lead to a discrepancy between private and public expenditures (social expenditures are equal to the sum of private and external ones, that is, nonpollutants and third parties), private expenditures are less than public expenditures. In order to reduce the overproduction of goods and services with negative external effects and to fill the underproduction of goods and services with positive external effects, that is, to transform external effects into internal, internalization of external effects is necessary. The essence of Pigu's corrective taxes is not to punish those who create negative externalities, not to compensate the external entity and even not to raise funds in the state budget, but to restore market equilibrium at a level that ensures optimum society, production and consumption of goods In developed countries, the state and society are trying to minimize balances. The basis was laid on the principle of organization of production, 
which means the use of raw materials and energy in an enclosed cycle. An enclosed cycle means a chain: primary raw materials - production - consumption secondary raw materials [16].

In developing countries to which Ukraine belongs, development is most often due to the use of natural resources and the slow introduction of intensive technologies.

While taking into account environmental influence, it is compulsory to analyze its intensity, which depends on the exposure time, the volume of the influence factor and its toxicity [16]. When analyzing the impact of waste on the ecosystem using the example of garbage that has been accumulated and must be transported to the landfill, we take into account the amount of waste that arrives at the landfill or the amount of toxic substances released into the ecosystem:

$$
V=\sum_{i=1}^{n} w_{i}\left(k_{i j}+l_{m}\right)
$$

where $V$ is the volume of the environmental impact factor (for example, waste), $w_{i}-$ is the daily average (monthly) toxic substance release rate (waste generation rate), $k_{i j}$ - is the time frame between deliveries from the sources of debris generation to the landfill, $l_{m}-$ is the time required for transportation of garbage from the place of generation to the landfill, $n-$ is the number of waste generation sites [17].

For example, I can observe such negative impacts that can be measured and quantified: the volume of toxic filtrate that is released into the soil over a period of time, the amount of toxic substances (on indicators) that are released into the air.

The total effect can be calculated by the formula:

$$
F=\left(K_{I}+V+K_{T}\right) t,
$$

where $K_{I}$ - is the intensity coefficient of the impact factor, $V-$ is the volume of the influence factor, $K_{T}-$ is the toxicity coefficient, $t-$ is the exposure time at the landfill.

So, with the income of a model company that grows sunflower seeds and sells them fried in packaging materials -800 thousand UAH ( 8 tons -4 ha), the profit excluding the cost of manufacturing the product, selling, transporting and paying taxes is about 150 thousand UAH. Although, taking into account the expenses of disposal of packaging materials (about 5,000 UAH at the price of waste disposal in Ukraine) and restoration of soil conditions to zero (with a yield of $2 \mathrm{t} / \mathrm{ha}$, about $60 \mathrm{~kg}$ of nitrogen, $30 \mathrm{~kg}$ of phosphorus and $50 \mathrm{~kg}$ of potassium are removed from the soil and other elements, while there is poisoning of the soil with preparations for deworming and weeds. The average price of restoration of the investigated field is 50 thousand UAH), then the profit will be about 96 thousand UAH.

From the results of the observation it follows that the average decrease in profit for a sample of ten enterprises in the field of agricultural production in the $\mathrm{Kiev}$ region is about 50 percent of total profit, which affects the profitability of the enterprise and the payback period. If each entrepreneur takes into account the negative impact on the ecosystem and minimizes it, along with a decrease in profits, gradual economic growth will begin in connection with the introduction of new technologies and the improvement of living standards. To do this, it is worth changing the legislation, making it more stringent, increasing fines and control.

With an increase of negative environmental influence factors, losses are added up and reduce the total profit of enterprises.

\section{Discussion}

The necessity for an integrated manner of the environmental burden at all levels of society should be reflected in taxes and fixed at the legislative level. This would help to reduce the negative influence on the environment and would be controlled by the state, the leadership of which should be interested in increasing the state budget and improving the life of the population [18].

When analyzing current expenditures and investments in environmental protection according to the State Statistics Committee of Ukraine [12], for the first sight, their volume grows, however, while analyzing the increase in the rate of negative influence, its accumulation effect and inflation processes, it becomes clear that the situation is getting worse every year (Fig. 3).

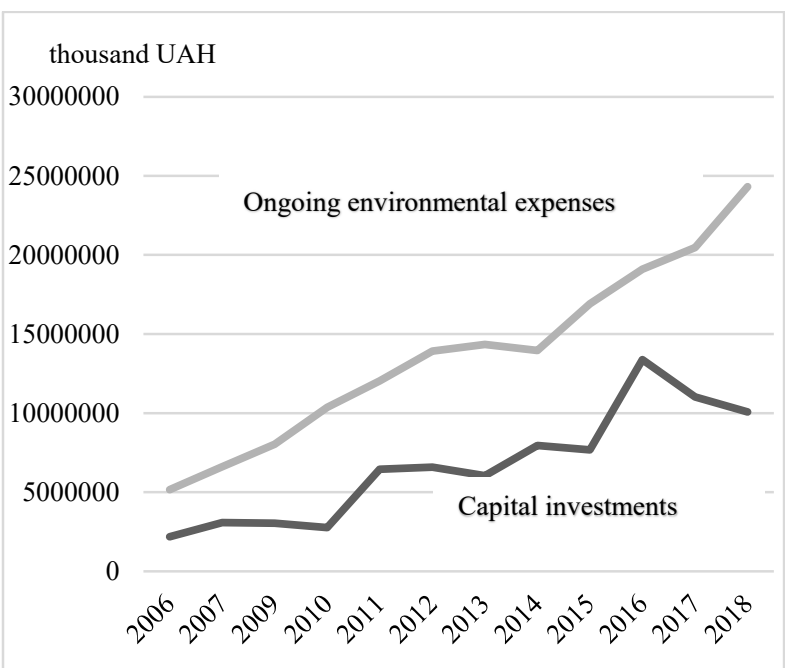

Fig. 3. Current Expenses and Capital Investments for Environmental Protection in Actual Prices on the Time Interval, thousand UAH [12]

Figure 3 shows a slight increase in expenditures and investments in environmental protection, however, in US dollar equivalent, the trend line has a smaller inclined angle and a lower coefficient of determination (which can be seen if you build a trend line, taking into account the inflation level in Fig. 4, in the interval from 2006 to 2018 ), which indicates the instability of the situation (greater deviation) and the slow growth of rate of cash proceeds, which is not able to significantly 
affect the negative consequences of anthropogenic influence.

Taking into account the effect of accumulation and corruption in Ukraine, the problem remains open and is constantly becoming more acute, affecting the quality of life of the population [19].

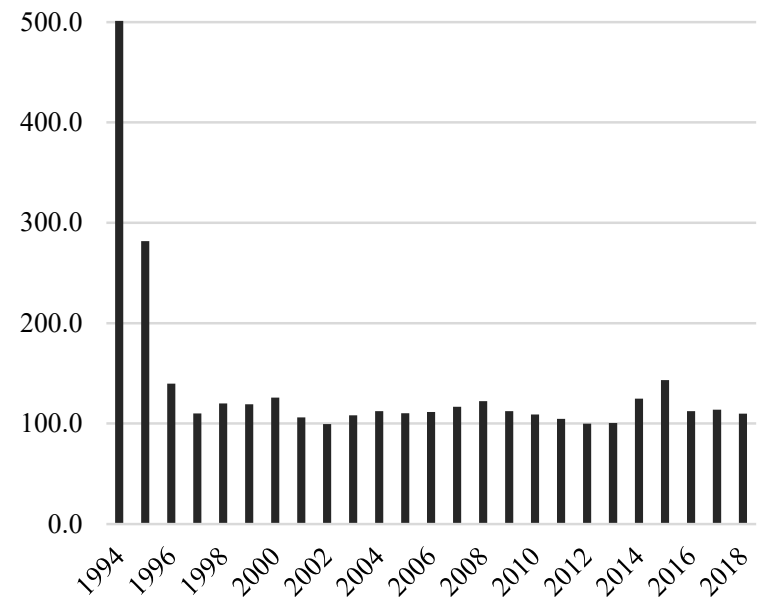

Fig. 4. The Inflation Rate in Ukraine on the Time Interval, 1992-2018, \% (till December of the previous year) [12]

Fig. 4 shows that the consumer price index is less than $100 \%$ only in 2002 and 2012 , it is more than $100 \%$ in other years of the researched interval, which indicates constant inflation with an average value of $37 \%$, which indicates a high rate of depreciation of the national currency, a decrease in the consumer population basket and the real costs of environmental measures [20]. The economic instability causes the outflow of investments and reduces the likelihood of investing in resource-saving technologies, while the structure of consumption balances changes towards fractions that have a long decomposition period, and the amount of packaging materials increases and becomes a threat to the existence of the natural environment [21].

The use of Leontyev-Ford models in calculating the resulting indicators is optimal, because the target function is not only income growth, but also a negative influence on the environment exposed to anthropogenic impact.

\section{Conclusions}

According to the growth of indicators of economic development (standards of living of population) of the country, the volumes of household and industrial wastes and industrial production are growing significantly. The natural power of the external environment is already becoming insufficient for the timely disposal of an increasing amount of household waste and negative externalities. The first countries to face with this problem were high-income countries and significant population densities. These are, first of all, highly developed countries of Western Europe.
The assessment methodology of economic indicators requires taking into account environmental impacts, which would better reflect the current state of both selected indicators and the general economic situation in the country. Minimization of the residual production while maximizing profits is proposed to be the targeted function which in turn will affect the performance and the overall level of the country's GDP.

But the result of evaluating the effectiveness of investments in solving the problems of environmental pollution in China showed that investments in the control and combating of water pollution and industrial waste pollution are not given due attention, i.e. public investment in these areas to combat pollution is ineffective [22].

The functioning of the Zero waste concept is considered to be the basis for further development which minimizes the impact of negative externalities.

The situation with the negative impact of human activities on the environment in Ukraine becomes more acute every year due to the accumulation of negative effects and a decrease or deterioration in the quality of natural resources. Environmental allocations are not enough to solve the problem, and corruption and the unwillingness of the government and entrepreneurs to change the situation still slows down the speed of implementation of new technologies and changes for the better.

\section{References}

1. C.O. Rusanescu, G. Paraschiv, S.S. Biris, M. Rusanescu, Environmental Awareness of Anthropogenic Impact. Hidraulica 83(2) (2016)

2. S.L. Vasenev, M.V. Rossinskaya, M.V. Bugaeva, V.V. Rokotyanskaya, M.U. Dikanov, Influence of "Quality of Living-Anthropogenic Impact on the Environment" System on Human Potential in Russia. Journal of Economic \& Management Perspectives 11(3), 1164-1176 (2017)

3. N.A. Ippolitova, Anthropogenic Impact of Industrial Production on the Environment (on the example of the Siberian region). IOP Conference Series: Earth and Environmental Science Volume 381(1) (2019)

4. V.I. Zakharov, E.A. Ilyushin, Signatures of anthropogenic impact have been detected in ionospheric travel disorders using regional GPS interferometry. IOP Conference Series: Earth and Environmental Science Volume 107 (1) (2018)

5. Z. Ozgeldinova, K.M. Janaleyeva, L.D. David, Z. Mukayev, M.A. Beisembayeva, G.T. Ospan, Estimation of potential stability of geosystem in conditions of anthropogenic impacts (Kazakhstan). Applied Ecology and Environmental Research 15 (4) (2017)

6. M. Stefunko, V. Zhilina, L. Shadrunova, T. Chekushina, Cadmium in Anthropogenic Biota Load. Metallurgical and Mining Industry 1 (2017) 
7. A. Generowicz, K. Gaska, G. Hajduga, Multicriteria Analysis of the Waste Management System in a Metropolitan Area, E3S Web Conferences Volume 44, $00043 \quad$ (2018). doi:10.1051/e3sconf/20184400043

8. W. McDowall, Y. Geng, B. Huang, E. Barteková, R. Bleischwitz, S. Türkeli, R. Kemp, T. Doménech, The Politics of the Circular Economy in China and Europe. Journal of Industrial Ecology 21 (3), 651-661 (2017)

9. O. Yankovyi, Yu. Goncharov, V. Koval, T. Lositska, Optimization of the capital-labor ratio on the basis of production functions in the economic model of production. Naukovyi Visnyk Natsionalnoho Hirnychoho Universytetu 4, 134140 (2019)

10. J.R. Hicks, Value and Capital (1998)

11. T. Odinokova, M. Bozhinova, M. Petrova, Promotion of Innovative Entrepreneurship Under Sustainable Development. E3S Web Conferences Volume 41, $04015 \quad$ (2018). doi:10.1051/e3sconf/20184104015

12. State statistics service of Ukraine (Kyiv, 2019), http://od.ukrstat.gov.ua/stat info/tyrizm/tyrizm1.ht m. Accessed 17 Sept 2019

13. V.D. Parondzhanov, Economics and ecology: a difficult path to dialogue. Social Sciences and the Present 3, 162-168 (2001)

14. O.P. Korzhevskaya, Investigation of the dynamic Leontiev-Ford model. An efficient economy 7 (2013)

15. R. Murray, Target - Zero Waste (Moscow, 2004)

16. Ana De Jesus et al., Eco- innovation in the transition to a circular economy: An analytical literature review. Journal of cleaner Production 172, 2999-3018 (2018)

17. E. Rosca, M. Arnold, J.C. Bendul, Business models for sustainable innovation - an empirical analysis of frugal products and services. Journal of Cleaner Production 162, 133-145 (2017)

18. M. Yeshchenko, V. Koval, O. Tsvirko, Economic policy priorities of the income regulation. Espacios 40 (38), 11 (2019)

19. K.G. Hoffman, Economic Assessment of Natural Resources and the Costs of Environmental Pollution (theory and methodology). (Moscow, 1975)

20. S. Labunska, M. Petrova, O. Prokopishyna, Asset and cost management for innovation activity, Economic Annals - XXI 165(5-6), 13-18 (2017). doi:10.21003/ea.V165-03

21. M. Petrova, N. Dekhtya, O. Klok, O. Loseva, Regional tourism infrastructure development in the state strategies. Problems and Perspectives in Management 16(4), 259-274 (2018). doi:10.21511/ppm.16(4).2018.22

22. A. Kravchenko, A. Hare, (2019). The relationship of economic development and environmental problems in modern china. Asia Pacific: Economics, Politics, Law 21 (2), 40-50 (2019). 